\title{
EREBEA
}

Revista de Humanidades

y Ciencias Sociales

NúM. 3 (2013), pp. 249-270

ISSN: 0214-0691

\section{RENOVACIÓN METODOLÓGICA DE LOS DICCIONARIOS BIOGRÁFICOS NACIONALES EN EL SIGLO XXI*}

\author{
Mikel Urquijo \\ Universidad del Pais Vasco
}

Resumen

Este artículo tiene como objetivo analizar el origen y desarrollo de los diccionarios biográficos nacionales en el contexto de la evolución de la biografía. En este análisis, observamos inicialmente los elementos que condicionan los diccionarios: ámbito geográfico y cronológico en el que se enmarcan, criterio de selección de los personajes a biografiar y de los biógrafos, esquema y fuentes de las biografías. A ello sumamos el análisis de la renovación organizativa y tecnológica de estas obras que han modificado sustancialmente los proyectos originales. Finalmente, y partiendo de lo dicho anteriormente, ofrecemos una propuesta para la renovación de estas obras en el siglo XXI.

Palabras Clave

Biografía de la Nación. Biografía Colectiva. Metodología. Renovación.

Fecha de recepción: 10 de abril de 2013

Fecha de aceptación: 31 de julio de 2013

\section{Abstract}

The aim of this article is to analyze the origin and development of national biographical dictionaries in the context of the evolution of biography. In this analysis we initially observe the elements that condition dictionaries: the geographical and chronological field in which they are framed, the criteria for selecting the personages whose biographies are to be written and for selecting biographers, the scheme and sources of the biographies. To this we add an analysis of the organizational and technical reorganization of these works that has substantially changed the original projects. Finally, based on the above, we set out a proposal for renovating these works in the twenty-first century.

\section{KEYWORDS}

National Biography. Colective Biography. Methodology. Renovation.

* Este trabajo se ha elaborado en el marco del proyecto de investigación Diccionario biográfico $y$ análisis prosopográfico de los parlamentarios de Vasconia, 1977-1982 (COD. HAR2011-24072) financiado por el Ministerio de Ciencia e Innovación y en las actividades del Grupo de investigación del Sistema Universitario Vasco (IT658-13) financiado por el Departamento de Educación, Política Lingüística y Cultura del Gobierno Vasco. 

"The life of a nation is told by the lives of its people" con estas palabras definían el Dictionary of American Biography, sus editores J.A. Garraty y M. Carnes ${ }^{1}$. Esta concepción de los diccionarios biográficos nacionales, originada en el siglo XIX, no ha dejado de tener actualidad en muchos lugares, entre los que podemos incluir nuestro país, en estos primeros años del siglo XXI.

En España los diccionarios biográficos nacionales son un tema de actualidad. La reciente edición del Diccionario biográfico español ha suscitado una importante polémica en la prensa nacional ${ }^{3}$, con algunos reflejos en la internacional ${ }^{4}$, en el mundo académico ${ }^{5}$ e incluso en el Parlamento ${ }^{6}$. Una obra que, sin duda, podemos calificar como polémica y que ha conseguido que la atención sobre la misma no proceda únicamente del mundo universitario.

El debate en torno a esta obra se ha centrado fundamentalmente en el contenido de la misma. Más exactamente en una parte del mismo, en sus voces más polémicas, como bien explica J. L. Ledesma. Pero consideramos necesario realizar una reflexión paralela a la que ya se ha producido sobre las biografías publicadas y sobre la idoneidad de los redactores, que nadie cuestiona en su totalidad. Por tanto, nuestro objeto de análisis no será nuevamente el contenido, sino el sentido

1 J.A. Garraty y M. Carnes, citado en R. Brookhiser, “"Who counted”, en New York Times Book Review, 23.01.2000, p. 14.

2 Diccionario Biográfico Español. Madrid: Real Academia de la Historia, 2009-2012, 50 volúmenes.

3 Dos ejemplos críticos con esta obra son los de los diarios: Público, que inicia sus artículos sobre este tema el 28 de mayo de 2011, y El País que lo hace el 30 de mayo de 2011. A partir de este momento se suceden los artículos hasta el mes de enero de 2013, en los que se trata sobre la edición de los últimos volúmenes editados de la obra.

4 J. Treglown, "Franco's friends - The old men who direct Spain's National Biography", en The Times Literary Supplement, no 5687 (30.03.2012), pp. 13-15.

5 Un análisis crítico sobre su contenido en J.L. Ledesma, "El Diccionario Biográfico Español, el pasado y los historiadores", en Ayer, no 88 (2012), pp. 247-265. Una iniciativa que va más allá de la crítica y que tiene como objeto contrarrestar las voces biográficas más polémicas de esta obra: A. VIÑAS (ed.): En el combate por la historia. La República, la guerra civil y el franquismo. Barcelona: Pasado y Presente, 2012.

6 Dos ejemplos de la atención del Parlamento a esta cuestión son el debate celebrado en el Congreso de los Diputados, el 12 de julio de 2011, sobre el Diccionario Biográfico Español (Diario de Sesiones del Congreso de los Diputados, 12 de julio de 2011) y las preguntas formuladas por el diputado D. Gaspar Llamazares al Gobierno sobre la subvención al Diccionario Biográfico Español (Boletin Oficial de las Cortes Generales. Congreso de los Diputados, 25 de abril de 2012, p. 77). 
y el diseño de la obra, que sin duda alguna tienen una importancia capital para mejorarla. Consideramos que la reflexión sobre la estructura y la planificación del trabajo nos puede ayudar a entender algunos de los problemas planteados en estas obras y a proponer nuevas ideas para mejorar los resultados. En definitiva, pretendemos realizar una reflexión general sobre el futuro de estos diccionarios en el siglo XXI, que sin duda se puede aplicar al caso español.

El objeto de estudio de estos diccionarios alcanza una dimensión que convierte la labor del historiador individual o de un reducido grupo de investigadores en insuficiente. El diseño de una obra de gran magnitud, tanto desde el punto de vista cronológico, geográfico y temático, el proceso de investigación y redacción de las biografías, la revisión de los textos o la gestión de la información exigen la construcción de una red de investigación que permitan llevar adelante el proyecto con éxito. Por otra parte, la competencia por los recursos dedicados a la investigación y las exigencias de los planes de Ciencia y Tecnología ${ }^{7}$, que son las herramientas a través de las que nuestros gobiernos planifican la investigación, nos obligan a la configuración de grupos y redes emulando a las estrategias de las ciencias experimentales. Debemos repensar nuestra estrategia de hacer historia a partir de la configuración de grupos y redes de investigación que permitan afrontar con éxito este tipo de proyectos. Por todo ello, los historiadores como el resto de los académicos del campo de las humanidades debemos contemplar la posibilidad de la investigación en grupo y en red con la finalidad de tener éxito en el desarrollo de proyectos de esta magnitud.

Esta reflexión sobre las biografías nacionales, que planteamos en este artículo no es nueva. En diferentes países se han elaborado nuevos proyectos ${ }^{8} \mathrm{o}$ modificado los existentes ${ }^{9}$, para subsanar los vacíos identificados en este tipo de

7 Un ejemplo se puede observa en los objetivos de la Decisión 2006/974/CE del Consejo, de 19 de diciembre de 2006, relativa al programa especifico Capacidades por el que se ejecuta el séptimo programa marco de la Comunidad Europea de acciones de investigación, desarrollo tecnológico y demostración (2007-2013), en http://europa.eu/legislation_summaries/research_innovation/general_framework/i23029_es.htm (consulta realizada el 21.03.2013). Esta misma filosofía se recoge en los planes nacionales y autonómicos españoles.

8 En el caso de los Estados Unidos no se plantearon renovar el Dictionary of American Biography, sino que se decidió realizar una nueva obra la American National Biography, E. Bryant, "Assessing American National Biography", en Library Journal, vol. 124, no 12 (1999), p. 82. También en el caso de Bélgica donde se optó por elaborar la Nouvelle biographie nationale, P. Gérin, "Nouvelle biographie nationale. Tome I", en Revue Belge de Philologie et d'Histoire, vol. 72 (1994), pp. 543-548.

9 Una explicación del proceso de revisión del Dictionary of National Biography elaborada por su editor en C. Matthew, "The new DNB", en History Today, vol. 43 (1993), pp. 10-13. Una explicación sobre la actualización del Dictionary of National Biography para cubrir su vacíos: escasa presencia femenina y visión del Imperio desde la metrópoli y en concreto desde Londres, ignorando las colonias y las regiones del Reino Unido, la inclusión de personas ordinarias para reflejar tipos sociales ignorados en la edición inicial, en E. Baigent, "The geography of biography, the biography of geographie: rewriting the Dictionary of National Biography", en Journal of Historical Geography, 
obras $^{10}$. En otros casos, se han elaborado obras diferentes a estos diccionarios para cubrir sus vacíos, como el diccionario sobre las feministas británicas ${ }^{11}$ para recuperar las biografías de las mujeres destacadas, dada su escasa presencia en el Dictionary of National Biography o la obra coordinada por J. Maitron sobre el movimiento obrero francés ${ }^{12}$.

Teniendo en cuenta los problemas señalados en este tipo de diccionarios, las diversas alternativas planteadas hasta el momento para superarlos y la necesidad de modificar nuestras estrategias de investigación, nos parece pertinente avanzar algunas reflexiones sobre el sentido, el contenido y la forma de este tipo de obras y la estrategia para su desarrollo.

\section{LA COLECCIÓN DE BIOGRAFÍAS: SU DEFINICIÓN}

El inicio del interés de la humanidad por la biografía se puede situar en el mundo antiguo ${ }^{13}$. Obviamente el sentido de las biografías, la manera de elaborarlas y su importancia en la historia han cambiado a lo largo del tiempo ${ }^{14}$. Desde la biografía de los faraones de Egipto plasmada en los jeroglíficos de sus tumbas, pasando por los doce césares de Suetonio, la biografía victoriana o la más reciente de Francisco Largo Caballero, elaborada por el recientemente fallecido profesor Julio Aróstegui, vemos un largo recorrido en el que ahora no entraremos.

Lo que deseamos destacar es el interés por el bios de las personas, que ha pervivido a lo largo del tiempo. Este preocupación por los individuos adquiere una forma particular en el periodo de la Ilustración. La búsqueda del saber enciclopédico también se plasma en el campo de la biografía, así comienza la edición de los primeros diccionarios biográficos universales ${ }^{15}$ que tratan de recopilar las

no 30 (2004), pp. 531-551.

10 Una visión crítica sobre los vacíos del Dictionary of National Biography en relación al criterio de inclusión de los personajes, a su visión metropolitana o a la omisión de aspectos de la vida privada de los biografiados, en P. Lastlett, "The Dictionary of National Biography: Missing Persons", en History Today, vol. 44, no 1 (1994), p. 49.

11 O. Banks, The Biographical Dictionary of British Feminists. Volume One: 1800-1930. New York: University Press, 1985.

12 J. Maitron (dir.): Dictionnaire Biographique du Mouvement Ouvrier Français. Paris: 19641993, 43 vols. J. Maitron y C. Pennetier (dirs.): Dictionnaire Biographique du Mouvement Ouvrier Français (Complément aux tomes 1 à 43: 1789-1939). Biographies nouvelles. Paris: 1997.

13 Una obra de referencia clásica en este sentido es A. Momigliano, The development of Greek biography, Harvard: University Press, 1971 (versión castellana con el título Génesis y desarrollo de la biografía en Grecia, editada por el Fondo de Cultura Económica en 1986).

14 Un recorrido por la evolución de la biografía desde la Antigüedad en F. Dosse, La apuesta biográfica. Escribir una vida. Valencia: PUV, 2007.

15 "The idea of collecting the lives of all the notable people who had ever lived was formulated by the scholarly polymaths of early modern Europe, who sought to classify and organise knowledge at a time when the printing revolution was producing a deluge of undigested information", en K. THOMAS, Changing Conceptions of National Biography. The Oxford DNB in Historical Perspective. 
vidas de todas aquellas personas de mérito desde el principio de los tiempos hasta ese momento.

Estos intentos ${ }^{16}$ que podemos situar a lo largo del siglo XVIII plantean un gran problema por su tremenda ambición, lo que los hace inacabables. Asunto este que nos permite plantear una primera cuestión sobre la conveniencia de delimitar un objeto de análisis biográfico abarcable en cualquier diccionario.

Pero estas biografías universales serán sustituidas progresivamente, aunque no del todo ${ }^{17}$, a lo largo del siglo XIX por otro modelo de colección de biografías con la creación de un nuevo sujeto histórico: las naciones ${ }^{18}$. Los nuevos estados nacionales en construcción deben educar a sus ciudadanos en los nuevos valores de la nación ${ }^{19}$. En este proyecto se sitúan los nuevos sistemas educativos nacionales, la elaboración de las historias nacionales y también la elaboración de la biografía de la nación, plasmada en los diccionarios biográficos nacionales que son "an integral part of the nation's mental furniture" 20 . En palabras de E. Renan "every nation needs its great men and its heroic past" ${ }^{21}$. El héroe clásico es sustituido por el héroe de la colectividad, de la nación, lo que hace "coincidir su determinación personal y la voluntad colectiva"22.

Cambridge: University Press, 2005, p. 4.

16 En el Reino Unido se edita la Biographia Britannica entre 1747 y 1751, posteriormente el New and General Biographical Dictionary, 1761, que culmina en The General Biographical Dictionary, editada entre 1812-1817, por A. Chalmers. Con la misma orientación enciclopédica se editan la General Biography de John Aikin en diez volúmenes (1799-1815) y la inacabada New General Biography de Hugh James Rose (1839-1848). Posteriormente, hay otro proyecto Biographical Dictionary impulsado por la Society for the Diffusion of Useful Knowledge, que no pasó de la A (1842-1844) y que en su totalidad hubiese tenido 150 volúmenes. Mas detalles sobre estas obras en J. Raven, "The Oxford Dictionary of National Biography: Dictionary or Encyclopedia?", The Historical Journal, vol. 50, no 4 (2007), p. 992 y ss.

17 En 1857 encontramos la obra de M. Hoefer (dir.): Nouvelle Biographie Générale depuis les temps les plus reculés jusqu'a nos jours, avec les renseignements bibliographiques et l'indication des sources a consulter. Paris : Firmin Didot Frères, Fils et Cie éditeurs, 1857-1866, 46 vols. Posteriormente en el siglo XX continua la edición de obras de ámbito supranacional como G. Garollo, Dizionario biografico universale. Milano : Ulrico Hoepli, 1907, 2 vols. o ya a finales de siglo A. Isaacs \& E. Martin (eds.): Longman Dictionary of 20th Century Biography. Harlow: Longman, 1985. En ellas continua vivo esa ambición universal.

18 Una explicación más detalladas sobre el significado de estas obras en M. Verga, "Il dizionario è morto. Viva i dizionari! Note per una storia dei dizionari biografici nazionali in Europa", Storica, no 40 (2008), pp. 7-32.

19 Sobre la creación de la historia de las naciones en un amplio sentido ver I. Porciani and J. Tollebeek (eds.): Setting the Standards. Institutions, Networks and Communities of National Historiography. New York: Palgrave MacMillan, 2012, especialmente los capítulos 2 al 7.

20 Baigent, "The geography of biography...", p. 531.

21 Citado en Thomas, Changing Conceptions of National Biography..., p. 10.

22 Dosse, La apuesta biográfica. Escribir una vida. p. 170. 
Este proceso se desarrollará desde el norte hacia el sur de Europa y desde las metrópolis europeas a sus dominios, en el caso británico. En estos grandes proyectos de biografías nacionales observamos dos modelos de organización: los de iniciativa pública y los de iniciativa privada ${ }^{23}$.

En los países de la Europa continental el impulso nació en los gobiernos o en instituciones públicas, que deseaban divulgar la vida de las personas de mérito de su país, ofreciendo un modelo a seguir a los ciudadanos en el proceso de construcción nacional. De acuerdo a este modelo se elaboraron los diccionarios biográficos nacionales de Suecia, Holanda, Austria, Alemania, Bélgica, Francia, Dinamarca, Noruega, Luxemburgo, Italia y España.

Frente a este elenco de biografías nacionales de impulso público, a través de los gobiernos, las academias de ciencias, etc., en el mundo anglosajón han primado los proyectos financiados por particulares, como en el Reino Unido, Estados Unidos y Canadá. Aunque han acabado siendo soportados, directa o indirectamente, por fondos públicos.

El examen de estas obras nos permite realizar una reflexión sobre su contenido y su proceso de elaboración.

En primer lugar, nos preguntamos sobre el marco temporal y geográfico al que se refieren los diccionarios, que nos ilustra también sobre su finalidad.

Estas obras se plantean como la biografía de la nación en el tiempo, a partir de su creación en el siglo XIX. Los estados nación se han configurado con unas fronteras determinadas, que no han sido invariables a lo largo del tiempo. Si observamos la evolución de las fronteras europeas vemos su gran movilidad a lo largo de la historia. Por tanto, la elección de un tiempo (¿cuándo iniciar la obra?) y de un espacio (¿qué territorio abarca?) determinados está íntimamente relacionado con el diseńo de la nación que se está elaborando y con un pasado coherente con esta ${ }^{24}$.

En el Dictionnaire de biographie française se incluyen los personajes fallecidos de todos los territorios franceses y sus colonias, en el tiempo que estuvieron bajo su dominio, en el periodo que va desde los Galos hasta 1925. En el caso de las colonias, Alsacia y Córcega, sólo se tiene en cuenta el periodo que estuvieron integradas en Francia. En otros territorios como el Franco Condado, Lorena o Saboya no se han excluido, porque han permanecido en la esfera de influencia francesa, aunque no formasen parte de Francia. No se incluyen los territorios del Imperio de la época napoleónica porque su unión fue muy

23 Una reflexión sobre el significado de este impulso público o privado en Verga, "Il dizionario è morto...", p. 21 y ss.

24 E. Baigent, "Nationality and Dictionaries of National Biography", en I. McCalman, J. Parvey and M. Cook (eds.): National Biographies \& National Identity. A Critical Approach to Theory and Editorial Practice. Canberra: The Australian National University, 1996, pp. 63-73. 
Diccionarios biográficos nacionales

\begin{tabular}{|c|c|c|c|}
\hline País & Título & Vols. & Edición \\
\hline Suecia & $\begin{array}{l}\text { Biographiskt Lexikon öfver namnkunnige Svens- } \\
\text { kamän } \\
\text { Svenskt biografiskt lexikon } \\
\text { Svenskt biografiskt lexikon }\end{array}$ & $\begin{array}{l}23 \\
10 \\
32\end{array}$ & $\begin{array}{l}1835-1857 \\
1857-1907 \\
1918-2002\end{array}$ \\
\hline Holanda & $\begin{array}{l}\text { Biografisch Woordenboek Der Nederlanden } \\
\text { Nieuw Nederlandsch Biografisch Woordenboek } \\
\text { Biografisch Woordenboek Van Nederland }\end{array}$ & $\begin{array}{c}24 \\
11 \\
5\end{array}$ & $\begin{array}{l}1852-1878 \\
1911-1937 \\
1979-2001\end{array}$ \\
\hline Austria & $\begin{array}{l}\text { Der grosse Oesterreichische Hausschatz: biogra- } \\
\text { phisches Lexicon des Kaiserthums Oesterreich } \\
\text { Neue Österreichische Biographie Ab 1815: Grosse } \\
\text { Österreicher } \\
\text { Osterreichisches Biographisches Lexikon 1815- } \\
1950\end{array}$ & $\begin{array}{l}60 \\
22 \\
12\end{array}$ & $\begin{array}{l}1856-1891 \\
1923-1987 \\
1957-2010\end{array}$ \\
\hline Bélgica & $\begin{array}{l}\text { Biographie Nationale } \\
\text { Suplementos a la Biographie Nationale } \\
\text { Nouvelle Biographie Nationale }\end{array}$ & $\begin{array}{l}28 \\
16 \\
10 \\
\end{array}$ & $\begin{array}{l}1866-1944 \\
1957-1986 \\
1988-2013 \\
\end{array}$ \\
\hline Alemania & $\begin{array}{l}\text { Allgemeine Deutsche Biographie } \\
\text { Neue Deutsche Biographie }\end{array}$ & $\begin{array}{l}56 \\
21 \\
\end{array}$ & $\begin{array}{l}1875-1912 \\
1953-2010 \\
\end{array}$ \\
\hline $\begin{array}{l}\text { Reino } \\
\text { Unido }\end{array}$ & $\begin{array}{l}\text { Dictionary of National Biography } \\
\text { Oxford Dictionary of National Biography }\end{array}$ & $\begin{array}{c}63+3 \\
60\end{array}$ & $\begin{array}{c}1885-1901 \\
2004\end{array}$ \\
\hline Noruega & Norsk Biografisk Leksikon & 19 & $1921-1983$ \\
\hline EEUU & $\begin{array}{l}\text { Dictionary of American Biography } \\
\text { American National Biography } \\
\text { American National Biography on-line }\end{array}$ & $\begin{array}{c}20 \\
24 \\
\text { on line }\end{array}$ & $\begin{array}{c}1926-1936 \\
1999 \\
2000-\end{array}$ \\
\hline Francia & Dictionnaire de Biographie Française & 19 & 1933-2009 \\
\hline $\begin{array}{l}\text { Dina- } \\
\text { marca }\end{array}$ & $\begin{array}{l}\text { Dansk biograhisk Leksikon } \\
\text { Dansk biograhisk Leksikon }\end{array}$ & $\begin{array}{l}27 \\
16\end{array}$ & $\begin{array}{l}1933-1944 \\
1979-1984 \\
\end{array}$ \\
\hline $\begin{array}{l}\text { Luxem- } \\
\text { burgo }\end{array}$ & $\begin{array}{l}\text { Biographie nationale du Pays de Luxembourg } \\
\text { depuis ses origines jusqu'a nos jours }\end{array}$ & 11 & $1949-1975$ \\
\hline Italia & Dizionario biografico degli italiani & 75 & $1960-2011$ \\
\hline Canadá & $\begin{array}{l}\text { Dictionary of Canadian Biography - Dic- } \\
\text { tionnaire Biographique du Canada }\end{array}$ & $\begin{array}{l}14 \\
\mathrm{Cd}\end{array}$ & $\begin{array}{c}1966-1989 \\
2000\end{array}$ \\
\hline Australia & Australian Dictionary of Biography & 17 & $1966-2011$ \\
\hline $\begin{array}{l}\text { Nueva } \\
\text { Zelanda }\end{array}$ & Dictionary of New Zealand Biography & 5 & $1990-2000$ \\
\hline Finlandia & Suomen Kansallsbiografia & 10 & $2002-2007$ \\
\hline España & Diccionario biográfico español & 50 & $2011-2012$ \\
\hline
\end{tabular}

* Esta relación no recoge todos los diccionarios que se han producido en el mundo. Únicamente pretende mostrar la continuidad de los mismos, con sucesivas reediciones o revisiones o la producción de nuevas obras, de sus inicios en 1835 hasta la actualidad. 
breve $^{25}$. Es decir, hablamos de los habitantes de los territorios de Francia antes de ser Francia.

En el caso italiano el Dizionario biografico degli italiani, abarca el periodo del siglo $\mathrm{V}$ al XX $\mathrm{XX}^{26}$, sin incluir el periodo romano. En su presentación se reafirma el espíritu nacionalizador de la obra, incluso iniciando su edición en el centenario de la Unidad: "Come ogni altra delle maggiori nazioni, anche l'Italia sente l'esigenza de una Biografia nazionale, a monumento storico della propia unità civile. (...) Adesso, per un fausto incontro di date, il primo volume del Dizionario Biografico degli Italiani vede la luce in coincidenza con le solenni manifestazioni che celebrano in questo paese il centenario dell'Unità" ${ }^{27}$.

En el mas reciente caso español, la obra se refiere a los personajes de todas las disciplinas y saberes de la Monarquía hispánica entre los siglos IV antes de Cristo hasta el siglo $\mathrm{XX}^{28}$. Es decir, hablamos de una obra referida a los españoles de antes de ser España. Subrayando esta idea nacionalizadora, el Director de la obra nos dice que el reunir en el Diccionario biográfico "a los "hombres de mérito" de las distintas tierras de España, desde la antigüedad hasta el presente, es una de las acciones vertebradoras que pueden contribuir con más eficacia a establecer nexos entre ellas [las tierras de España] y a fomentar el entendimiento y la concordia"29. Aunque este sentido nacionalizador pueda parecer fuera de lugar en el s. XXI, debemos recordar que este proyecto se gesta en 1999, cuando estaba muy vivo el debate sobre la enseñanza de la historia en España ${ }^{30}$, al que contribuyeron muchos colegas ${ }^{31}$ universitarios y también la Real Academia de la Historia ${ }^{32}$.

Pero sin duda, el caso de la Biographie Nationale de Bélgica es el más significativo para entender el significado nacionalizador de estos diccionarios. En 1845 el gobierno belga decidió la creación de la Comisión de la Biographie Nationale ${ }^{33}$. Frente

25 J. Balteau, M. Barroux, M. Prevost (dir.): Dictionnaire de biographie française. Paris: Librairie Letouzey et Ané, 1933, vol. I., pp. V-VI.

26 Una explicación sobre el debate en relación con el marco cronológico de esta obra cuando se concibió, en Verga, "Il dizionario è morto...", p. 17 y ss.

27 DIZIONARIO biografico degli italiani. Roma: Istituto della Enciclopedia Italiana, 1960, vol. I, p. VII.

28 Presentación del Diccionario Biográfico Español en http://www.rah.es/pdf/Informacion-DBE. pdf (consulta realizada el 21.03.2013).

29 Diccionario Biográfico Español, vol. I, p. 12.

30 Ver el Informe sobre los textos y cursos de Historia en los centros de Enseñanza Media (Madrid, 23.06.2000), elaborado por la RAH y el informe patrocinado por la Fundación Bofill Els Llibres D'Història. L'ensenyament de la Història i Altres Històries, (Julio de 2001), coordinado por Antoni Segura. Ambos en http://servidormanes.uned.es/mciud/documentos/debate_humanidades.htm.

31 Ver el numero 30 de la revista Ayer, del año 1998, referido a este tema.

32 Ver la obra colectiva, España. Reflexiones sobre el ser de España. Madrid: Real Academia de la Historia, 1998.

33 La Comisión estaba formada por miembros de la Académie Royale des Sciences, des Lettres et des Beaux-Arts de Belgique, presidida por el presidente de la Academia y formada por el secretario de 
al proyecto, planteado en el seno de la Comisión, de realizar tres síntesis históricas: Letras, Ciencias y Bellas Artes, se afirmó la idea de una "biografía nacional" que recogiese todas las personas de mérito, que llevasen fallecidas más de diez años.

Los personajes biografiados debían haber nacido en Bélgica o en los territorios que dependían de la Bélgica del momento, es decir, se biografiaba a los belgas de antes de nacer Bélgica ${ }^{34}$. Este concepto de inclusión realizado desde la realidad política actual de los estados, también incluyendo antiguas colonias e imperios está basado en una clara voluntad nacionalista. Esta inspiración nacionalista que denota el criterio de selección de los biografiados se ve reforzada, en el caso de Bélgica, con el acuerdo de la Comisión que obligaba a que la redacción de las biografías fuese realizada únicamente por ciudadanos belgas ${ }^{35}$.

Los cuatro ejemplos citados no son la excepción sino la norma, aunque existen algunos casos que la alteran como el de Egipto ${ }^{36}$. Las nuevas naciones se reconocen en un espacio, el territorio nacional, y un tiempo, que suele estar ligado a un periodo en el que consideran que se realiza la unidad de la nación.

Una vez delimitados el tiempo y el espacio que son la base de la nación se elegirá a los personajes que serán biografiados. A los naturales de esta "nación" se añadirán aquellos que han tenido un papel destacado en la historia de la misma. Parafraseando a Plutarco las virtudes de los grandes hombres narradas en las biografías servían de espejo para el comportamiento de los lectores ${ }^{37}$.

Pero ¿cómo son elegidos estos personajes? ${ }^{38}$ En general se elige a los que se denomina como personajes eminentes. En Inglaterra se denominan "noteworthy inhabitants of the British Islands and the Colonies" ${ }^{39}$, en Escocia "eminent

la misma y seis miembros, dos por cada Sección (Letras, Ciencias y Bellas Artes).

34 En el siglo XX se publicó una biografía nacional referida a los flamencos, Nationaal Biografisch Woordenboek. Bruselas, Kominklijke Valaamse Academiën van België, 1964-1968, 3 vols., citado en P.-H. Laurent, "Nationaal Biografisch Woordenboek", American Historical Journal, no 70 (1970), pp. 2082-2083.

35 Un relato de la historia de esta Comisión y de la elaboración de la obra en J. LAVALLEYE, Historique de la Commision de la Biographie Nationale. Bruxelles: Établissements Émile Bruylant, 1966. También ver ACADÉMIE ROYALE DES SCIENCES, DES LETTRES ET DES BEAUXARTS. Biographie Nationale. Bruxelles: H. Thiry Van Buggenhoudt, Impremeur-Editeur, 1866, pp. IX-XXXVIII.

36 En este diccionario sobre Egipto se toma como criterio incluir a los personajes que han aportado algo importante a la historia de Egipto desde finales del siglo XIX, no se remonta a los faraones, A. Goldschmidt, Biographical Dictionary of Modern Egypt. London: Lynne Rienner, 2000.

37 M. Plutarco, Vidas paralelas. Madrid: Ed. Gredos, 1985-2010, 7 vols.

38 Una visión crítica sobre el proceso de selección en el Dictionary of National Biography en C. BELL, "Some Comments on the Use of Directories in Research on Elites, with Particular Reference to the Twentieth-Century Supplements of the Dictionary of National Biography". en British Political Sociology Yearbook. Vol. 1 Elites in Western Democracy (1974), pp. 161-171.

39 L. Stephen and S. Lee (eds): The Dictionary of National Biography. Oxford: University Press, 1973 ( $\left.8^{\mathrm{a}} \mathrm{ed}\right)$, vol. I, p. LXII. 
Scotsmen" ${ }^{40}$, en Bélgica "Belges ayant joui d'une certaine notoriété"41, en Italia "tutti coloro che hanno avuto un particolare rilievo nei vari aspetti e momento della vita e della civiltà italiana dal V secolo ai nostri giorni” ${ }^{2}$, en España "cuantos participaron y se destacaron en la administración y gobierno, en las acciones guerreras y en las paces, en las artes, en las letras y en las ciencias en los territorios hispánicos, en los de ultramar y en los transpirenaicos que formaron lo que suele denominarse "Monarquía hispánica" ${ }^{3}$ o en Canadá "all noteworthy inhabitants of the Dominion of Canada" 44 .

La homogeneidad en el criterio de los diccionarios de la mayoría de los países nos conduce a otra pregunta ¿cómo se define la eminencia? ${ }^{45}$ ¿esta eminencia es considerada de la misma manera a lo largo del tiempo? ${ }^{46}$ Esta cuestión ha sido discutida desde hace años en diferentes países, ya que el concepto de personaje eminente ha variado con el tiempo y en función de quién realiza esta selección y su concepto de la historia y de la nación ${ }^{47}$. Por otra parte, ¿el propio concepto de eminencia sería el más adecuado desde el punto de vista historiográfico?

En el Dictionary of National Biography entre los personajes eminentes encontramos a las personas que han sido relevantes en la vida británica, tanto por su aproximación o relación con el poder como por ser los líderes de los grupos enfrentados al mismo, pero ¿qué sucede con la gente común de los grupos subalternos? En la renovación de algunos diccionarios se plantean, que si el objeto del Diccionario es la biografía de la nación también se debería incluir a personajes que nunca han destacado pero que representan a tipos importantes en la vida de la nación: "What has changed, therefore, is not the intelectual rationale or method of compilation but our perspective on what constitutes influence and

40 Th. Thomson (ed.): A Biographical Dictionary of Eminent Scotsmen. With Numerous Authentic Portraits. Bristol : Thoemmes Presss, 1996 (es una reedición), vol. VI, p. VI.

41 LAVALLEYE, Historique de la Commision de la Biographie Nationale, p. 25.

42 DIZIONARIO biografico degli italiani. vol. I, p. XVII.

43 Diccionario Biográfico Español. Madrid: Real Academia de la Historia, 2009, vol. I, p. 12.

44 G.W. Brown (ed.): Dictionary of Canadian Biography. Toronto: University Press, 1966, vol. I, p. XVI.

45 No resulta sencilla la selección de los personajes. Un ejemplo fuera de Europa sobre la discusión del criterio con el que se ha realizado la selección puede ser el de la India, en su Dictionary of National Biography (Calcuta, Institute of Historical Studies, 1972, 4 vols.), ver M. S. Yanuck, "Dictionary of National Biography", en Journal of Asian Studies, vol. 37, no 1 (1977), pp. 154-156.

46 Una muestra de este cambio puede ser el de los inventores. La visión ofrecida por la primera edición del Dictionary of National Biography en la selección de los inventores difiere de la actual y manifiesta una determinada concepción del papel de la tecnología en la transformación de las sociedades contemporáneas, ver C. MAcleod and A. Nuvolari, "The Pitfalls of Prosopography. Inventors in the Dictionary of National Biography", en Technology and Culture, vol. 47, no 4 (2006), pp. 757-776.

47 J. Walter, "Seven questions about National Biography”, en McCalman, Parvey and Cook (eds.): National Biographies \& National Identity..., pp. 16-34. 
historical value" ${ }^{48}$.

Así en el Australian Dictionary of Biography han incluido en sus últimos volúmenes personajes de este tipo o en el Dictionary of New Zealand Biography se ha añadido una publicación adicional titulada $A$ People's History ${ }^{49}$, que recoge un gran número de biografías de personajes subalternos que ejemplifican "qualities of human vitality, resilience and endurance, a quirky dignity among those of all sorts and condition who strove to stand upright in a strange land" 50 y que amplia el concepto de biografía nacional ${ }^{51}$.

Pero esta propuesta de incluir la biografía de la gente corriente es posible para los tiempos más próximos, aunque bastante más difícil para los más lejanos por la dificultad de documentar estas biografías. Por otra parte, es especialmente relevante en países como Australia y Nueva Zelanda en los que su historia nacional no se identifica con grandes héroes, como en España, Francia o Inglaterra, sino por gente corriente que emigró a estos territorios en tiempos recientes y que han contribuido a crear estas naciones ${ }^{52}$.

Otra cuestión, importante en la selección de los personajes, es si estos personajes deben haber fallecido o se puede hablar de ellos en vida. Decía Leslie Stephen, editor del Dictionary of National Biography, a Thomas Hardy en 1889: "I only beg that you will not ge into the Dictionary yourself" 53, expresando el criterio comúnmente aceptado de que los personajes biografiados deben haber fallecido. Así es en el Reino Unido ${ }^{54}$, en Francia ${ }^{55}$, Italia ${ }^{56}$ o Luxemburgo ${ }^{57}$, por citar algunos ejemplos.

El caso español resulta extraño, ya que contrariamente a otros diccionarios ha elegido incluir personajes vivos ${ }^{58}$. Esto plantea un gran problema cuando hay cam-

48 P. Carter, "Fromt the Cracks of History", en History Today, vol. 54, no 10 (2004), pp. 18-20.

49 W.H. Oliver, A People's History, Illustrated Biographies from The Dictionary of New Zealand Biography, Volume One 1796-1869. Willington: 1992.

50 Citado en Baigent, "The geography of biography...”, p. 541.

51 Citado en Baigent, "The geography of biography...”, p. 540.

52 Una búsqueda de nuevas visiones de la construcción colectiva de la identidad en un contexto geográfico bien diferente se puede encontrar en Korea, S. Park, "At the crossroads of literature and history: Maninbo (10,000 lives) as social biography", en Rethinking History, vol. 16 (2012) no 3, pp. 417-441.

53 Citado en S.P. Rosenbaum, "The Dictionary of National Biography: Missing Persons", en English Literature in Transition, 1880-1920, vol. 37, no 4 (1994), p. 535.

54 Stephen and LEE (eds): The Dictionary of National Biography, vol. I, p. LXII

55 Balteau, Barroux, Prevost (dir.): Dictionnaire de biographie française., vol. I., pp. V-VI.

56 DIZIONARIO biografico degli italiani, vol. I, p. XVII.

57 En el caso de Luxemburgo establecen un plazo de 20 ańos después de la muerte para evitar los panegíricos, J. Mersch (ed.): Biographie nationale du Pays de Luxembourg depuis ses origines jusqu'a nos jours. Luxembourg: Imprimerie de la Cour Victor Buck, 1949-1975, 11 volúmenes (22 fascículos)

58 Esta inclusión de personajes vivos en el Diccionario Biográfico español, contradice la infor- 
bios importantes en la vida de estos personajes. Un ejemplo sería el de D. Gerardo Díaz Ferrán ${ }^{59}$ que en este momento está sometido a un proceso judicial, que puede tener consecuencias muy relevantes en su vida personal y profesional. ¿Cómo actualizar estas biografías en aspectos esenciales de las mismas en una obra impresa?

Este ejemplo, y otros que se podrían suscitar dada la actualidad político-económica española, nos llevan a considerar que en una obra abierta ${ }^{60}$, como lo es un diccionario biográfico nacional parece más adecuado no incluir personajes vivos, como lo hacen en la mayor parte de los países, para tener una visión completa del personaje antes de ser biografiado.

Podría ser diferente si tratásemos de un trabajo cerrado, que selecciona a los personajes por una actividad determinada, que ya se ha realizado, lo que justificaría la inclusión de personas vivas o si planteamos una obra abierta a frecuentes actualizaciones, como el caso del Oxford Dictionary on National Biography o la American National Biography ${ }^{61}$ que nos permita la revisión de cada biografía.

Otro problema a resolver en el diseño de estos diccionarios es la selección de los biógrafos. No sólo importa a quién biografiamos sino también quién realiza esta labor. El criterio ideal suele ser buscar a una persona distante del biografiado, aunque no siempre resulta sencillo ${ }^{62}$, porque los personajes fallecidos recientemente, en ocasiones, no han recibido la atención de los historiadores. En el caso del Diccionario Biográfico español esta situación se complica por la decisión de incluir personajes vivos, lo que hace más difícil seleccionar a biógrafos que conozcan al personaje si no son personas que han tenido relación con el mismo.

En el caso del Diccionario Biográfico español ha habido críticas por la relación personal entre biógrafos y biografiados, de manera destacada en la biografía de

mación ofrecida por la prensa en el inicio del proyecto. El diario El País (25.07.1999) informaba que las biografías se harían sobre los personajes fallecidos. Ignoramos si fue un error de la periodista o que la Real Academia de la Historia modificó su criterio en el proceso de elaboración de la obra. Unos ańos más tarde, el Director Técnico del proyecto decía que se incluirían a personajes "nacidos antes de 1950", cosa que no se ha hecho como ejemplifica la inclusión del Príncipe de Asturias y sus hermanas, nacidos en la década de los sesenta, ver. J. Olmedo, "El Diccionario biográfico español de la Real Academia de la Historia”, en Cercles. Revista d'Història cultural, no 10 (2007), p. 98.

59 Diccionario Biográfico Español, vol. XVI, pp. 91-92.

60 Un ejemplo de obra en continua actualización es Oxford Dictionary of National Biography, una explicación sobre este proceso de actualización en B. HARRISON, "National biography for a computer age", en History Today, vol. 51, no 8 (2001), pp. 16-18 y sobre el resultado en A.D. Harvey. "The Oxford Dictionary of National Biography", en History Today, vol. 54, no 10 (2004), pp. 58-61.

61 Esta última, a pesar de ser una obra en constante renovación, mantiene el criterio de incluir las biografías de personas fallecidas, E. Tallent, "American National Biography", en Library Journal, vol. 125 , no 9 (2000), p. 133.

62 Sobre las diferentes biografías en función de la relación entre biografiado y biógrafo, ver A. Alpers, "Biography - The Scarlet Experiment", en D. Salwak (ed.): The Literary Biography. Problems and Solutions. London: MacMillan Press, 1996, pp. 12-21. 
Franco, que ha sido escrita por D. Luis Suárez Díez, Académico de la Historia y Vicepresidente de la Fundación Nacional Francisco Franco. En principio, no debería haber habido problemas en la redacción de las biografías si los responsables de las mismas hubieran seguido las normas aprobadas por la propia Real Academia de la Historia, en las que se instaba a no realizar valoraciones personales, criterio compartido por los investigadores de otros países que han analizado los diccionarios biográficos ${ }^{63}$. Un ejemplo de ello sería el volumen del Dictionary of National Biography, dedicado a la década 1971-1980, en la que se recogen buenas biografías realizadas por personas ligadas a los biografiados ${ }^{64}$. En ocasiones no encontraremos mejores biógrafos de algunos personajes que personas ligadas a las Fundaciones que estudian al personaje, ahora bien, si los redactores son verdaderos especialistas en la materia.

Otra cuestión que nos planteamos al enfrentarnos al análisis de este tipo de diccionarios es el propio esquema de las biografías. En los diccionarios, habitualmente, la estructura de la biografía es cronológica y su contenido puede diferir bastante de unos casos a otros. Esto dificulta su utilización en estudios posteriores de una manera sistemática. ¿No sería interesante plantearse el diseño de un ficha biográfica más cerrada que facilite su utilización posterior? ${ }^{65}$. Creando una ficha en la que se organice la biografía de acuerdo a los círculos vitales del personaje: su círculo familiar, su círculo formativo, su círculo económico-profesional, su círculo social y el círculo referido a la actividad por la que el personaje es biografiado: política, economía, deportes, arte,..., podríamos plantearnos su utilización de manera sistemática para el análisis de grupos sociales ${ }^{66}$. Algo similar se ha realizado en el diseńo de la edición del Maitron en CD para las biografías del periodo 1940-1968, que se han concebido para su utilización en un estudio prosopográfico posterior ${ }^{67}$.

63 "Relevant quirky I like in biographical writing, but it is time to dispense with the eccentric idiosyncratic, which has frequently characterized contributions to the Dictionary of National Biography", en J. Powell, "The Dictionary of National Biography: Missing Persons", en Albion: A Quarterly Journal Concerned with British Studies, vol. 26, no 1 (1994), p. 114. En el caso belga P. Gérin también insiste sobre la necesaria distancia entre biógrafo y biografiado, P. Gérin, "Nouvelle biographie nationale. Tome II”, en Revue Belge de Philologie et d'Histoire, vol. 77 (1999), p. 577.

64 P.F. Clarke, "The Dictionary of National Biography, 1971-1980", en English Historical Review, vol. 103, no 406 (1988), p.156.

65 P. Levillain nos habla de "dizionari comparativi tra paesi, epoche, con metodi di analisi identici, cercando di sistematizzare l'analisi scientifica e di passare del prestigio letterario del genere alla foga della comprensione", en A. Riosa (a cura di): Biografia e Storiografia. Milano : Franco Angeli, 1983, p. 47.

66 Esta cuestión la plantea P. Gérin en la renovación del diccionario belga, P. Gérin, "Nouvelle biographie nationale. Tome I", en Revue Belge de Philologie et d'Histoire, vol. 72 (1994), p. 547.

67 Ver el apartado "Les tems de la prosopographie et de la sociobiographie historique", en "Avant propos au Cédérom", en J. Maitron (ed.): Dictionnaire Biographique du Mouvement Ouvrier Français [CD-Rom]. Paris: Ed. de l'Atelier, 1997. 
Por último, debemos tener en cuenta la importancia de las fuentes para un buen trabajo biográfico. Parece lógico en un trabajo histórico exigir que las fuentes sean originales, como estableció hace más de un siglo el Dictionary of National Biography ${ }^{68}$, a fin de garantizar un apoyo empírico adecuado a las biografías. Pero por otra parte, se debe considerar la extensión de las fuentes a incluir en la biografía. Si la convertimos en un listado exhaustivo de fuentes de archivo, bibliográficas, hemerográficas, iconográficas, digitales, su utilidad para la persona que consulta la obra puede verse dificultada. Por tanto, debemos considerar con atención los límites para la enumeración de las fuentes, dado que este tipo de obras tiene un público importante entre no especialistas o jóvenes estudiantes para los que las fuentes deben ser seleccionadas, a fin de que les resulten de utilidad para ampliar sus conocimientos sobre el personaje ${ }^{69}$.

LA RENOVACIÓN ORGANIZATIVA Y TECNOLÓGICA Y SUS EFECTOS EN LOS CONTENIDOS

A los aspectos señalados anteriormente, que son los que definen el diccionario, se suman en la última década algunos cambios que han contribuido a la evolución de estas obras. En primer lugar, la ampliación y apertura de la estructura editorial. Y en segundo lugar, la modificación del soporte sobre el que se editan las biografías.

Para desarrollar esta idea analizaremos el proceso de cambio de las dos obras más innovadoras: la American National Biography y el Oxford Dictionary of $\mathrm{Na}$ tional Biography, que nos pueden ofrecer algunos ejemplos interesantes sobre la renovación de este tipo de obras.

En ambos casos el proceso de renovación del proyecto se ha realizado a partir de la apertura de la estructura de redacción, configurando una red de investigadores permanente. El paso de un reducido grupo de investigadores que gestionaba el proyecto a una amplia red de centenares de personas es un elemento capital para la revisión y actualización de una obra de esta magnitud. Se trata de adaptarnos al paradigma de la innovación abierta, desarrollado por Henry W. Chesbrough, que nos indica que las ideas valiosas pueden provenir tanto de dentro como de fuera del grupo responsable del proyecto ${ }^{70}$.

En el proyecto de la American National Biography se optó por abrir su labor a un gran número de académicos ${ }^{71}$. La nueva estructura editorial consta de una editora general, un comité editorial asesor de catorce miembros y

68 S. Lee, "The Dictionary of National Biography. A Statistical Account", en Stephen and LEE (ed.): The Dictionary of National Biography, vol. I, p LXIV.

69 Bryant, "Assessing American National Biography", p. 82.

70 H.W. Chesbrough, Innovación abierta. Barcelona: Plataforma editorial, 2009 , p. 137 y ss.

71 Bryant, "Assessing American National Biography", p. 82. 
diecinueve comités editoriales asesores temáticos ${ }^{72}$, compuestos por doscientos cincuenta miembros. En total, doscientos sesenta y cinco académicos procedentes de diferentes universidades mayoritariamente de los Estados Unidos. En palabras de sus editores, esto es lo que convierte a la obra en verdaderamente nacional: "By virtue of its decentralized editorial structure and the diversity of its editors and authors, the American National Biography has earned its name" 73 .

Esta nueva estructura editorial se ha abierto aún más a la hora de definir el nuevo proyecto. Para ello, consultaron a los directores de las sociedades históricas de cada estado para que propusiesen nuevos personajes para ser biografiados, a lo que se sumarían las propuestas individuales de académicos de todo el país. A partir de las mismas, los comités editoriales han seleccionado las biografías a realizar y han propuesto los biógrafos. Las nuevas voces biográficas son revisadas, en primer lugar, por el editor que las ha encargado y por el American National Biography Staff que realizan sugerencias para su corrección. Posteriormente, la versión corregida es enviada al American National Biography Staff de la Oxford University Press que realiza una segunda revisión previa a la publicación. En definitiva, una apertura a los académicos del país a la participación en las propuestas y una gran apertura de la estructura de redacción para conseguir desarrollar con éxito este proyecto.

En el proyecto del Oxford Dictionary of National Biography se ha seguido un modelo similar. La labor se ha dividido en doce áreas ${ }^{74}$, que son tratadas como un subproyecto cada una y un área transversal que tiene como objetivo garantizar una presencia equilibrada de mujeres en el proyecto. En cada área hay un editor consultor nombrado por el editor general. Junto a estos editores consultores responsables de un área temática hay dos más con responsabilidad de la edición. A su vez, se ha creado un equipo de editores asociados, 373 personas, con la responsabilidad de un tema dentro del área a la que están adscritos. Estos últimos han revisado los artículos publicados en el Dictionary of National Biography, una

72 Las áreas son seis generales (Historia precolonial y colonial hasta 1763, Historia Política, Diplomática y Militar 1763-1850, Historia Política, Diplomática y Militar 1850-1878, Historia Política, Diplomática y Militar 1878-1914, Historia Política, Diplomática y Militar 1914-1945, Historia Política, Diplomática y Militar 1945-1990), doce temáticas (Arte, Arquitectura y Artes aplicadas, Artes escénicas, Ciencia y Tecnología, Ciencias Sociales, Deportes, Derecho y judicatura, Educación, Literatura, periodismo y literatura popular, Medicina, Negocios, Reforma social, Religión) y una denominada Miscelanea.

73 Preface, American National Biography online en http://www.anb.org/foreward.html (consulta realizada el 11.03.2013).

74 Las áreas son seis generales (General antes de 1500, General s. XVI, General s. XVII, General s. XVIII, General s. XIX, General s. XX) y seis temáticas (Arte y Arquitectura 1500-2000, Literatura 1500-1779, Literatura 1780-2000, Ciencia 1500-2000, Negocios y mundo del trabajo 1500-2000, Medicina 1500-2000). 
media de 140 cada uno, para establecer cuales deben ser revisados o sustituidos y también proponer la elaboración de artículos sobre nuevos personajes y sus redactores. Junto a estos hay un equipo encargado de la publicación formado por un gran número de editores. Al igual que en el caso americano se realizó una consulta a miles de miembros de sociedades científicas y lectores de revistas sobre las debilidades y fortalezas del diccionario que fueron evaluadas por los editores, con lo que se planificó el nuevo proyecto. Finalmente, como en el caso de los Estados Unidos se ha establecido un detallado proceso de revisión de los artículos previamente a su publicación ${ }^{75}$.

Un segundo aspecto capital en la transformación de este tipo de obras ha sido la edición digital. Estas obras en su origen se presentaron en forma impresa, como no podía ser de otra manera en el siglo XIX. Las sucesivas actualizaciones de las mismas, han provocado que el número de apéndices alcanzase un volumen que los hacía inmanejables ${ }^{76}$. Por ello, en los años noventa algunos diccionarios biográficos de gran extensión, como el Dictionnaire Biographique du Mouvement Ouvrier Français ${ }^{77}$ con cuarenta y cuatro volúmenes o el Dictionary of Canadian Biography ${ }^{78}$ con catorce volúmenes, se reeditaron en soporte CD-Rom. Este nuevo formato ofrecía importante ventajas frente a las anteriores ediciones en papel. En primer lugar, permitía que las actualizaciones se incluyesen en la obra con sucesivas reediciones completas, dado el reducido coste de las mismas, eliminando los apéndices de actualización. En segundo lugar, posibilitaba la corrección y actualización de las voces con un coste reducido. En tercer lugar, facilitaba y agilizaba la búsqueda de la información deseada. En cuarto lugar, convertía obras de referencia como eran este tipo de diccionarios en nuevas bases de datos que ofrecían una mayor utilidad a la información recopilada ${ }^{79}$. Aunque el paso al CD también era criticado, ya que se podían cuestionar los resultados obtenidos con

75 Editorial structure and procedure, en http://www.oup.com/oxforddnb/info/print/intro/intro3/ (consulta realizada el 14.03.2013).

76 The Dictionary of National Biography se editó en 22 volúmenes (1885-1901). Posteriormente, se editaba un volumen de actualización cada década hasta 1980 y a partir de este año cada lustro. A lo que se añade en 1993 un nuevo volumen, The Dictionary of National Biography. Missing Persons, dedicado a las personas desde el principio de la historia que no se habían incluido anteriormente y que en ese momento consideraban debían haber sido incluidas (sobre estos volúmenes "Missing Persons from the Dictionary of National Biography", en English Historical Review, vol. 105 , no 415 (1990), p. 283). Una cantidad de volúmenes que hacía poco manejable la obra. La nueva versión en 2004 tiene 60 volúmenes.

77 Maitron (ed.): Dictionnaire Biographique du Mouvement Ouvrier Français [CD-Rom]. Esta nueva edición incluye las biografías originales tras su revisión.

78 R. Cook and R. BELANGER (dir.): Dictionary of Canadian Biography / Dictionnaire Biographique du Canada [CD-ROM]. Toronto - Quebec: University of Toronto Press - Université Laval, 2000.

79 Ver el apartado "De l'ouvrage de référence à la base de données", en "Avant propos au Cédérom", en Maitron (ed.): Dictionnaire Biographique du Mouvement Ouvrier Français [CD-Rom]. 
una considerable inversión ${ }^{80}$.

$\mathrm{Al}$ mismo tiempo otros proyectos pasaban a ofrecer sus contenidos en formato papel y on-line ${ }^{81}$, como el caso de la American National Biography ${ }^{82}$, desde 1999 (papel) y 2000 (on-line) $)^{83}$ o el Oxford Dictionary on National Biography ${ }^{84}$, desde 2004 en ambos soportes. Por tanto, un formato de edición más barato y sencillo de hacer permitiría una reedición más frecuente ${ }^{85}$. Con ello, la inclusión de personas vivas sería menos problemática porque a la vez que se añaden nuevas voces, se pueden modificar las ya publicadas, con cierta periodicidad.

La American National Biography es, probablemente, el mejor ejemplo de diccionario biográfico nacional on line y de las posibilidades que abre. En primer lugar, se produce un incremento constante del número de biografías, 500 al año, sin esperar a costosas reediciones o a la publicación de apéndices. En segundo lugar, estas biografías ofrecen, junto al texto clásico, acceso a imágenes de la Biblioteca del Congreso, referencias cruzadas a través del hipertexto a otras voces del diccionario y enlaces con otros sitios web seleccionados en razón de su temática. En tercer lugar, se incluye un sistema de búsquedas, que va más allá del nombre del personaje, y ofrece la posibilidad de realizar una búsqueda avanzada a partir de la profesión, el género, las fechas de nacimiento o defunción, etc. En cuarto lugar, para poder citar la información con corrección ofrece la fecha de la consulta en la ficha de resultados ${ }^{86}$, lo que resulta de utilidad en una fuente en continua actualización. Es decir, el diccionario decimonónico se convierte en una enciclopedia digital que permite ampliar la información al lector a través de la Red. Estas posibilidades convierten a esta obra en una fuente de gran utilidad y fácil manejo para investigadores o curiosos.

\section{Conclusiones}

Tras este somero repaso al origen, conceptualización, elaboración y renovación de los diccionarios biográficos nacionales podemos presentar algunas conclusiones de utilidad para repensar estas obras, que pueden ser de interés para el caso español.

80 M.J. Daunton, Virtual representation: the History of Parliament on CD-ROM”, en Past \& Present, no 167 (2000), pp. 238-261.

81 El debate sobre la conveniencia de la edición en soporte digital se plantea hace más de una década D. Stoker, "The new Dictionary of National Biography and the future of the printed reference work", en Journal of Librarianship and Information Science, vol. 32, no 1 (2000), pp. 1-3.

$82 \mathrm{http} / / /$ www.anb.org.

83 Una explicación del contenido y forma, con especial incidencia en las posibilidades de búsqueda dentro de la American National Biography, en G. Golderman and B. Connolly, "American National Biography Online", en Library Journal, supl. Net Connect (2001), pp. 44-47.

$84 \mathrm{http} / /$ www.oxforddnb.com/

85 El Oxford Dictionary on National Biography se actualiza tres veces al año y la American $\mathrm{Na}$ tional Biography se actualiza semestralmente.

86 Tallent, "American National Biography”, pp. 133-134. 
La primera cuestión que nos planteamos es si tiene sentido hoy en día plantearnos un diccionario biográfico nacional cuando la nación convive con otras formas de organización política supranacionales ${ }^{87}$.

Es cierto, que estas obras responden a un momento de nuestra historia y a la preocupación de los "constructores de la naciones" por legitimar su existencia. Pero también resulta evidente que construir estas biografías nacionales, definiendo la nación en el tiempo y en el espacio desde el presente hacia el pasado, como se han venido realizando, puede ser algo que debamos repensar.

Prueba del interés de esta reflexión es la falta de una definición clara de la nación en la mayor parte de estas obras. Es interesante la reflexión sobre esta cuestión que se realiza en la introducción al Oxford Dictionary of National History: "the DNB asserted nationality but carefully avoided defining it" ${ }^{88}$. Esta indefinición intencionada permite la inclusión de personas que vivieron en el territorio de Gran Bretańa antes de que existiese un estado reconocible y la presencia de personas originarias de todos los territorios británicos y ultramarinos.

Esto resulta especialmente importante en los países que han dominado un imperio colonial, desaparecido en la actualidad, como España, Francia o el Reino Unido. En el caso de las nuevas naciones la cuestión resulta diferente. La American National Biography entiende como americano a "someone whose significant actions occurred during his or her residence within what is now the United States or whose life or career directly influenced the course of American history" ${ }^{89}$. Aunque también en estos casos se plantean dudas sobre el tratamiento ofrecido a los habitantes de estos territorios con anterioridad a la creación de los estados actuales.

Esta primera reflexión sobre el marco de las biografías nacionales condiciona la selección de los personajes a incluir en las mismas. En definitiva, el criterio de inclusión/exclusión en estas obras.

En primer lugar, se deben revisar los diccionarios para tratar de cubrir los vacíos que se puedan detectar. Ya hemos mencionado en las páginas anteriores la escasa presencia femenina ${ }^{90}$ en la mayor parte de estas obras o la de los personajes destacados de las regiones periféricas. También la de personajes que no se consideraron eminentes a partir de los parámetros decimonónicos con los que se planificaron estos proyectos. Hay que abrir los diccionarios a la diferencia, es decir

87 H. Schweiger, "Global Subjects: The Transnationalisation of Biography", en Life Writing, vol. 9, no 3 (2012), pp. 249-258.

88 Citado en Principles of inclusion, en http://www.oup.com/oxforddnb/info/print/intro/intro2/ (consulta realizada el 14.03.2013)

89 Preface, American National Biography online en http://www.anb.org/foreward.html (consulta realizada el 11.03.2013).

90 P. Grimshaw, "Female Lives and the Tradition of Nation-Making", en McCalman, Parvey and Cook (eds.): National Biographies \& National Identity..., pp. 35-53. 
a los que no forman parte de la elite concebida en el sentido convencional ${ }^{91}$, en palabras de Colin Matthew, editor del Oxford Dictionary of National Biography, "the new dictionary is not merelly a roll-call of the great and the good, but also a gallimaufry of the eccentric and the bad"'?2.

En relación con la inclusión de personas vivas, parece más adecuado esperar al fallecimiento de los personajes para incluir su biografía dado que los motivos de selección no siempre son claros y estables, aunque un modelo de diccionario en edición digital permitiría subsanar este problema.

Por otra parte, se debe considerar con atención la propuesta desarrollada en Australia, Nueva Zelanda o Estados Unidos para incluir hombres y mujeres ordinarios en los diccionarios, en sus renovaciones, que representen a una buena parte de la ciudadanía anónima de la nación.

También merece la pena considerar la opción de incluir, junto a las voces biográficas individuales, voces colectivas referidas a familias, grupos, etc. dado que las personas no solo viven su vida, también viven la del grupo social en el que se ubican.

En cualquier caso, este cambio de orientación en la selección de los personajes a biografiar no resulta sencillo como muestran las críticas de J. Raven al nuevo Oxford Dictionary of National Biography ${ }^{93}$. Lo que nos conduce a considerar que el proceso de reflexión sobre el objeto del diccionario debe estar permanentemente abierto en un proceso de renovación continua.

Para llevar adelante esta renovación parece más adecuado organizar el trabajo en subproyectos temáticos que tengan en cuenta la cronología y el espacio. Debe abrirse el proyecto a las aportaciones de académicos de todo el territorio sobre el que se interesa el diccionario. Ejemplos interesantes se pueden observar en el caso de la American National Biography y en el Oxford Dictionary of National Biography, que desarrollan el paradigma de la innovación abierta tanto en su estructura editorial como en la apertura de consultas a un buen número de personas.

Por otra parte, la división del proceso de actualización en trabajos parciales puede permitir repensar la ficha biográfica, en el sentido indicado en las páginas anteriores, de manera que las biografías resultantes ofrezcan mayor coherencia y puedan ser explotadas posteriormente, como propone J. Maitron en la revisión del Dictionnaire Biographique du Mouvement Ouvrier Français.

El resultado de estos subproyectos conformará el nuevo diccionario, como se ha realizado en el Reino Unido ${ }^{94}$, que multiplicará el volumen de las biografías

91 J. Walter, "Seven questions about National Biography", en McCalman, Parvey and Cook (eds.): National Biographies \& National Identity..., pp. 16-34.

92 Citado en Principles of inclusion, en http://www.oup.com/oxforddnb/info/print/intro/intro2/ (consulta realizada el 14.03.2013).

93 Raven, "The Oxford Dictionary of National Biography...", pp. 991-1006.

94 Matthew, "The new Dictionary of National Biography", pp. 10-13. 
lo que inevitablemente conduce a su edición digital. Los diccionarios biográficos nacionales en papel no son viables en este momento dado los enormes costes de la edición, su poca capacidad para la actualización y corrección y las limitaciones que tiene para organizar la información. Un buen modelo, por las posibilidades que ofrece, es el de la American National Biography.

La edición digital permite que la obra este continuamente en un proceso de revisión, corrección y actualización con un coste reducido. Amplia la posibilidad de búsqueda, desde la alfabética tradicional, a rastreos de términos y cronologías en todo el texto, no sólo en los títulos de las voces biográficas. Permite una sencilla inclusión de imágenes ${ }^{95}$, y enlaces a otros términos dentro del mismo diccionario, a documentos digitalizados en portales temáticos, etc. En definitiva, amplia las posibilidades de información más allá del propio diccionario, para las personas que desean un conocimiento más profundo de los personajes o de los temas ligados a ellos. ¿Acabarán los diccionarios convertidos en enciclopedias??96.

Otra cuestión a considerar con atención es la extensión de las biografías. ¿Deben ser trabajos de gran erudición que aspiren a ser la referencia académica principal sobre el personaje? o ¿̇deben ser biografías más breves dirigidas a un público menos especializado? En el caso del Oxford Dictionary of National Biography, su nuevo editor Colin Matthew, considera que quién busque información sobre un personaje muy destacado de la historia británica tiene a su alcance otro tipo de fuentes más exhaustivas. Por tanto, se inclina por entradas más breves, que confieren al Diccionario una gran utilidad ${ }^{97}$.

A modo de conclusión final el Diccionario Biográfico español debería ser repensado a la luz de las experiencias desarrolladas en otros países. La estructura actual ${ }^{98}$ de cinco comisiones permanentes ${ }^{99}$, cinco comisiones especiales ${ }^{100}$ y dos comisiones externas ${ }^{101}$, formadas por un total de cuarenta y dos personas, es a todas luces insuficiente. Si tenemos en cuenta que el Diccionario Biográfico español

95 En la American National Biography y el Oxford Dictionary of National Biography se incluyen imágenes sobre las biografías.

96 Raven, "The Oxford Dictionary of National Biography...”, pp. 991-1006, y especialmente p. 1004 y ss.

97 Matthew, "The new Dictionary of National Biography", pp. 10-13.

98 En la presentación de la obra se menciona que en el año 2000 se contó con la colaboración de las academias iberoamericanas y los académicos correspondientes en unas jornadas sobre el proyecto, pero no se ha incluido a estas personas en la estructura que se menciona en esta misma presentación, ver http://www.rah.es/diccbiografico.htm y http://www.rah.es/pdf/InformacionDBE.pdf.

99 Las Comisiones son: Indias, Historia Eclesiástica, Antigüedades y Estudios Clásicos, Estudios Orientales y Medievales y Heráldica.

100 Las Comisiones son: Ciencias Económicas, Sociales y Políticas, Letras y Humanidades, Arte y Música, Historia Política y de la Administración (se subdivide en tres: Medieval, Moderna y Contemporánea), Historia (varios) y Espectáculos.

101 Las Comisiones son: Historia Militar y Ciencias y Aplicaciones. 
ofrece 40.000 biografías con una estructura de cuarenta y dos personas, mientras la American National Biography ofrece 17.435 biografías con una estructura de doscientos sesenta y cinco personas, la conclusión evidente es que resulta necesario repensar esta estructura.

Tomando como referencia el modelo de los Estados Unidos debería reconsiderarse como primer paso la propia estructura de comisiones. En segundo lugar, debería aumentar el número de miembros de las mismas o de editores asociados a las mismas para poder realizar su trabajo. En tercer lugar, esta ampliación debería hacerse en las universidades, centros de investigación y sociedades de estudios de España y América.

Esta nueva estructura editorial debería dirigir un proceso de revisión de las voces publicadas, abierto a un gran número de académicos, como se ha hecho en la American National Biography o en el Oxford Dictionary of National Biography, que puede conducir al mantenimiento, revisión ${ }^{102}$ o supresión ${ }^{103}$ de las mismas y a la ampliación con nuevas biografías.

Por otra parte, esta nueva estructura editorial debería establecer un nuevo protocolo de revisión de las biografías, ya que el actualmente en vigor no ha tenido un resultado adecuado, a la vista de las polémicas suscitadas sobre el contenido de una parte de las mismas. Un procedimiento similar al americano podría ser el modelo a seguir, con una revisión inicial por parte de uno de los editores, una segunda revisión por parte de la comisión temática y una tercera revisión formal por el equipo de edición. Desde luego este debe ser uno de los puntos capitales en la renovación del proyecto.

Por último, se debe considerar el abandono definitivo de la edición en papel y dar el paso al soporte digital. La nueva obra debería diseñarse en una plataforma digital que facilite la corrección, renovación, actualización y ampliación de la información a través de la Red, con la introducción de enlaces a ampliación de contenidos, documentación, etc.

En definitiva, un diccionario para el siglo XXI.

102 Se han reescrito el 63\% de las voces del antiguo Dictionary of National Biography y se han introducido, inicialmente, 16.000 nuevas biografías, Thomas, Changing Conceptions of National Biography...

103 En el caso del American National Biography se han eliminado 9.000 biografías del Dictionary of American Biography porque consideraban que no tenían interés en la actualidad, Bryant, "Assessing American National Biography", p. 82. 